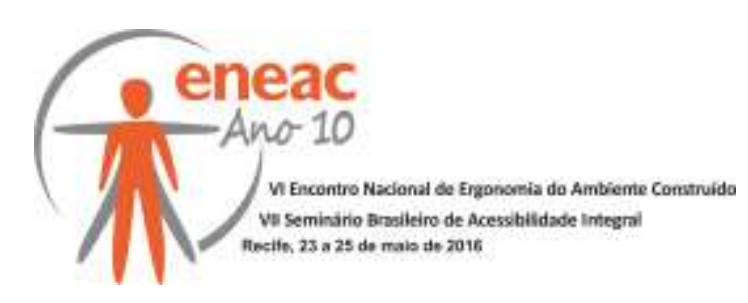

\title{
O OLHAR DO USUÁRIO ACERCA DA ACESSIBILIDADE NA UNIVERSIDADE: O (CONTRA) EXEMPLO DO CAMPUS I DA UFPB
}

\author{
SARMENTO, Bruna Ramalho (1); \\ COSTA, Angelina Dias Leão (2)
}

(1) LACESSE,UFPB / PPGAU,UFRN, Doutoranda em Arquitetura e Urbanismo

e-mail:brunarsarmento@hotmail.com

(2) LACESSE,UFPB / PPGAU, UFPB, Doutora em Engenharia Civil

e-mail:angelinadlcosta@yahoo.com.br

\begin{abstract}
RESUMO
Este artigo concentra a atenção no usuário do campus I da UFPB, a fim de verificar como ele qualifica o sistema de circulação de pedestres da Instituição. A avaliação recorreu à elaboração de um questionário , que foi aplicado e tabulado de modo a se chegar a um diagnóstico sobre o sistema. Os resultados demostraram que o campus I da UFPB proporciona condições mínimas de mobilidade ao usuário, sendo necessárias intervenções que promovam ao pedestre maior acessibilidade na universidade.
\end{abstract}

Palavras-chave: acessibilidade; campus universitários; usuário.

\begin{abstract}
This article focuses attention on campus I user of UFPB's campus, in order to check how it qualifies the pedestrian circulation system of the institution. The evaluation resorted the elaboration of a questionnaire that was applied and tabulated in order to reach a diagnosis on the system. The results showed that of UFPB's campus provides minimum conditions of mobility to the user, requiring interventions to promote greater accessibility to pedestrians at the university.
\end{abstract}

Keywords: accessibility; university campus; user.

\section{INTRODUÇÃO}

As aglomerações urbanas são interligadas por extensas redes de estruturas de circulação que conectam toda uma paisagem formando o sistema de circulação de pedestres, que representa importante parcela do ambiente construído e é responsável pela circulação entre as estruturas funcionais de uma cidade, o que o torna fundamental para toda a mobilidade urbana e a acessibilidade a sistema é condição essencial para que todos os indivíduos possam viver em sociedade (BAPTISTA 2010).

Do mesmo modo que nas cidades, o ambiente universitário, também chamado de cidade universitária, deve apresentar um sistema de circulação que considere a diversidade humana e a qualidade de vida da população, visto que, a cada ano essas instituições recebem uma grande diversidade de usuários, seja devido a sua idade, cultura, status social 


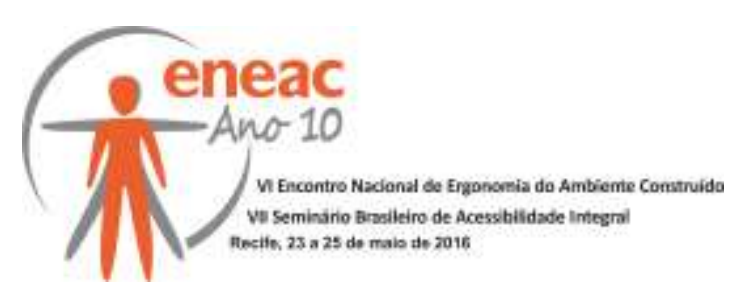

ou mesmo habilidades físicas, sensoriais e cognitivas. E segundo Bins Ely e Ghizi (2006), esta diversidade deve ser respeitada, pois, desde que reconhecida e aceita, enriquece e humaniza a comunidade acadêmica.

Contudo, para Duarte e Cohen (2004), a educação só poderá ser considerada verdadeiramente democrática quando a universalidade orientar o desenho de todos os edifícios e espaços dentro de um campus, de modo que todos os indivíduos tenham acesso sem barreiras às salas de aula, laboratórios, bibliotecas, espaços esportivos e de convivência, etc., visto que, segundo Ornstein (2011), quando as instituições de ensino apresentam um ambiente urbano e os edifícios acessíveis abre-se uma grande porta para a inclusão, possibilitando a circulação de qualquer pessoa, sem restrições.

Segundo Sarmento (2012), no campus I da Universidade Federal da Paraíba (UFPB), em João Pessoa - PB, o sistema de circulação possibilita ao usuário diversos modos de deslocamento, tais como: a caminhada, a bicicleta, a motocicleta e o automóvel particular; mas a Instituição não dispõe de um transporte público interno, sendo atendida no anel viário externo pelo transporte público municipal.

Dentre os modos de deslocamento utilizados no campus I este artigo enfoca a modalidade pedonal, por constituir a forma mais natural e direta de provimento individual de meio de transporte, como também por entender que, apesar da extensão do campus (161,75 ha), é possível transpor as distâncias interpartes - centros de ensino - através da caminhada, que, de acordo com Vasconcellos (2001), é feita com conforto e segurança quando conta, principalmente, com acessibilidade das calçadas e sinalização específica de travessias e vias.

Desse modo, o usuário, apesar de não ter um olhar técnico, possui um ponto de vista bastante significativo na avaliação, visto que, segundo Margarido (1989 apud ORNSTEIN e ROMÉRO, 1992), "o grande experimentador é o usuário que, no dia-a-dia, testa todos os aspectos da construção. A singularidade desse pesquisador é que ele não possui formação específica, sendo seus depoimentos, entretanto, da maior importância".

Nesse quadro, este artigo tem como objetivo verificar como o usuário qualifica o sistema de circulação de pedestre do campus I da UFPB, por meio da aplicação de questionário. O trabalho realizado é parte de uma dissertação defendida em 2012, que avaliou a acessibilidade na UFPB (SARMENTO, 2012). Embora na dissertação tenha sido utilizada uma estratégia de pesquisa multimétodos (SOMMER; SOMMER, 2002; GUNTHER; ELALI; PINHEIRO, 2008), esse artigo trabalha a opinião dos usuários sobre esse sistema.

\section{MÉTODO}

Um dos principais modos de coleta de informações em ciências sociais e áreas afins (GUNTHER, 2008; RHEINGANTZ et al, 2009), além de ser ágil, o questionário possibilita identificar o perfil dos respondentes e verificar sua opinião sobre as questões investigadas. Neste caso específico, ele permitiu o verificar como o usuário qualifica o sistema de circulação de pedestres do campus I da UFPB.

Os dados foram coletados de forma direta e por amostragem, com plano probabilístico estratificado (STEVENSON, 1981). No cálculo do número de questionários o campus I teve sua população fixa e ativa estratificada em três subgrupos: técnicos administrativos, docentes e discentes de graduação e pós-graduação, a partir de dados oficiais ${ }^{1}$ fornecidos

\footnotetext{
${ }^{1} \mathrm{O}$ quantitativo referente à população fixa e ativa do Campus I da UFPB foi obtido, no caso dos técnicos administrativos e dos docentes, junto a Pró-Reitoria de Gestão de Pessoas da UFPB (PROGEP) e se referem ao mês de julho de 2011 , e no caso
} 


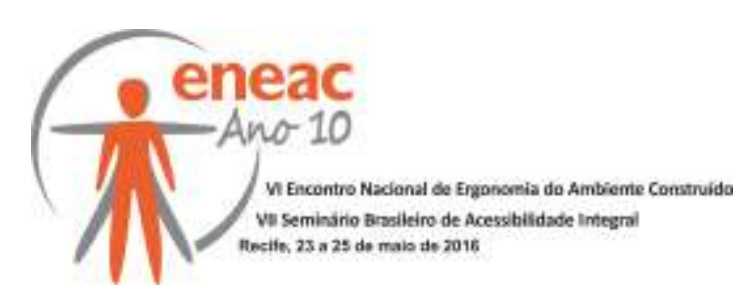

pela Instituição (Tabela 1). Para o cálculo da amostra foi considerada significância de $50 \%$ $(p=1 / 2)$, erro de amostragem de e $\leq 5 \%$ e $95 \%$ de intervalo de confiança, sendo definida a necessidade de 380 respondentes, distribuídos proporcionalmente em função de cada estrato considerado (Tabela 2).

TABELA 1: Quantificação da população por estrato.

\begin{tabular}{c|c|c|c|c}
\hline Estratos (k) & Tec. Admin. & Docentes & Discentes & Total \\
\hline Nk & 3.228 & 1.889 & 24.107 & 29.224 \\
\hline
\end{tabular}

Onde: $\mathrm{Nk}=$ tamanho da população no estrato $\mathrm{k}$.

Fonte: Dados oficiais fornecidos pela UFPB (2012).

TABELA 2: Quantificação da amostra por estrato.

\begin{tabular}{c|c|c|c|c}
\hline Estratos (k) & Tec. Admin. & Docentes & Discentes & Total \\
\hline $\mathrm{Nk}$ & 42 & 25 & 313 & 380 \\
\hline
\end{tabular}

Após a determinação do número de questionários a serem aplicados partiu-se para a elaboração do questionário, que versou sobre questões relacionadas ao perfil do usuário e caracterização do sistema de circulação de pedestres do campus I da UFPB. O instrumento abordou os itens: Acessos e Circulação, Mobiliário Urbano, Comunicação e Sinalização e Estacionamentos; além de Dados Pessoais para a caracterização da amostra.

Os questionários foram aplicados durante todo o mês de abril de 2012, no período diurno e noturno. Porém, antes disso, foi realizado um pré-teste, para identificar possíveis incoerências no instrumento, que também foi submetido e aprovado pelo Comitê de Ética em Pesquisa em Seres Humanos da UFPB.

\section{2. ÁREA DE ESTUDO}

O campus I da UFPB está localizado no bairro Castelo Branco, Zona Leste da cidade de João Pessoa, PB. Limita-se com a Mata do Buraquinho (Mata Atlântica remanescente com uma extensa área de preservação permanente - APP), o bairro dos Bancários e a Rodovia Federal BR 230 (Figura 1). Ele foi criado em 1955 e federalizado em 1960, possui uma área total de 161,75 ha, aos quais estão incorporados 03 núcleos de preservação permanente, resultando 117,8 ha de espaços ocupáveis, que congregam 97 cursos de graduação, distribuídos em 13 centros de ensino. Conta, ainda, com setores de vivência, administrativos, de serviços e esportivo, com grandes áreas construídas e bolsões de Mata Atlântica preservada (SARMENTO, 2012). 


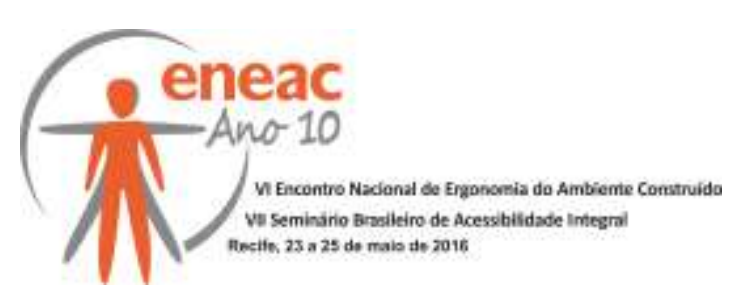

Figura 1 - Mapa da malha urbana da cidade de João Pessoa-PB combinada com a imagem aérea de inserção do campus I da UFPB no bairro Castelo Branco e áreas limite.

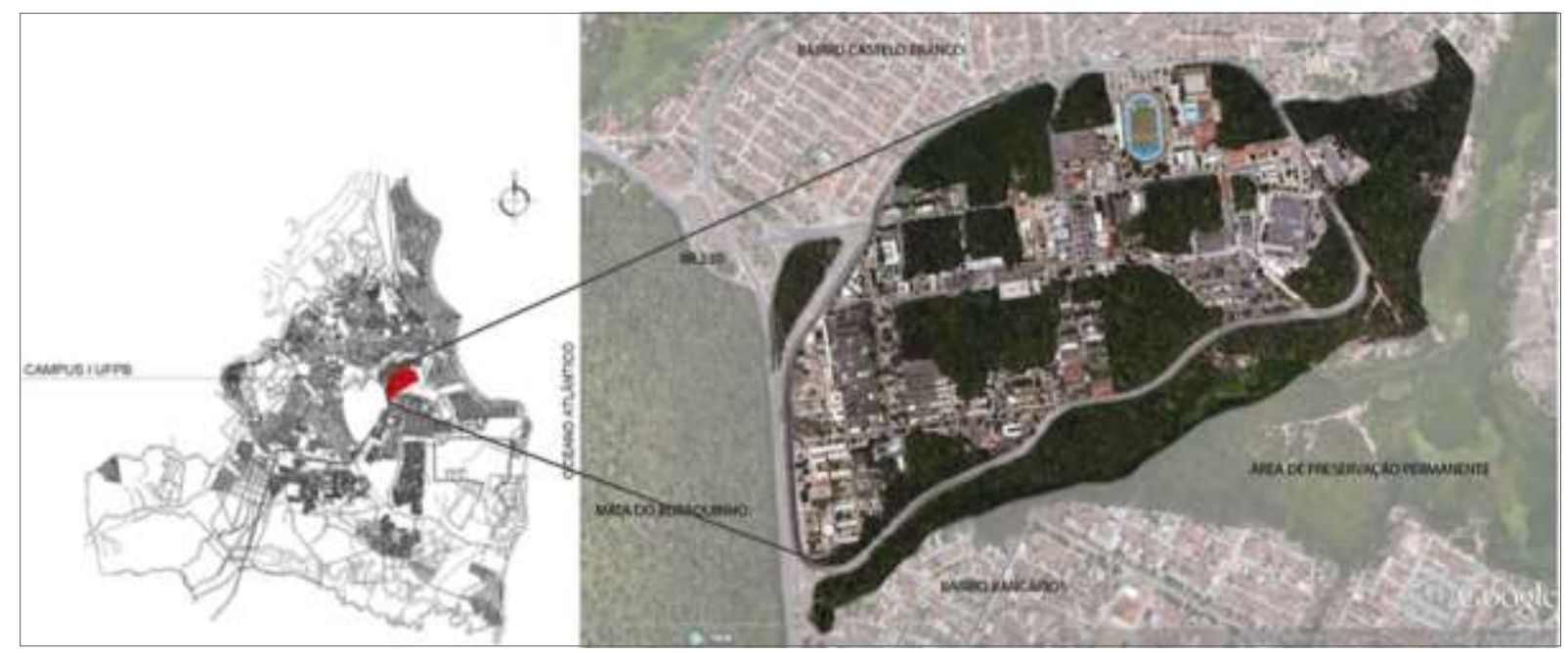

Fonte: Costa et al (2009) (imagem JP); Google Earth (2016) (imagem campus), modificada pela autora.

O campus I apresenta topografia majoritariamente plana (com alguma declividade a Leste, próximo ao Hospital Universitário) e 9 acessos: 5 de uso misto, para pedestres e veículos e providos de guaritas; e 4 exclusivos para pedestres, próximo a pontos de transporte coletivo. Seu processo de ocupação evoluiu gradativamente a partir da década de 1970, tendo se acentuado nos anos 2000, com o advento do Programa REUNI, quando a UFPB intensificou obras e criou novos cursos (UFPB, 2011). Entre 2007 e 2012 o número de estudantes de graduação aumentou em $72 \%$, o quadro de docentes cresceu $25 \%$ e o de servidores em 18\% (UFPB, 2007). O Plano REUNI-UFPB (UFPB, 2007) previa a construção de $34.125 \mathrm{~m}^{2}$ de novas edificações no campus I e reforma de $12.205 \mathrm{~m}^{2}$, ações estruturantes que serviram de base física à implantação de 30 novos cursos.

Ao longo da ocupação do campus I da UFPB, nesses últimos 60 anos, foram se ramificando diversas estruturas que compõem o sistema de circulação de pedestres (Figura 2):

- As calçadas, entendidas como as passagens públicas pavimentadas e descobertas;

- As passarelas, ou seja, passagens públicas pavimentadas, térreas e cobertas;

- Os estacionamentos formais pavimentados, também utilizados pelos pedestres para circulação;

- As travessias de vias, sinalizadas com faixa de pedestre.

Essas estruturas interligam os diversos centros de ensino do campus, proporcionando ao pedestre uma base física para circulação. 


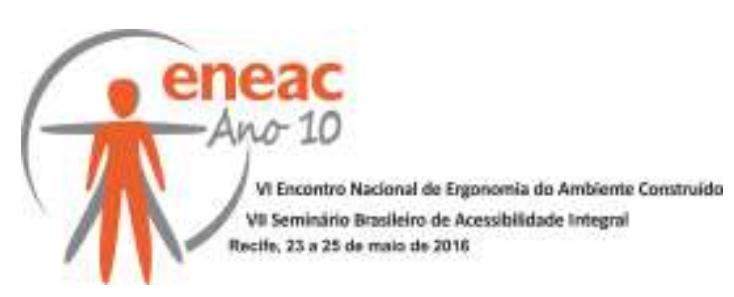

Figura 2 - Mapa identificando as estruturas que compõem o sistema de circulação de pedestres do campus I da UFPB - Situação em janeiro de 2012.

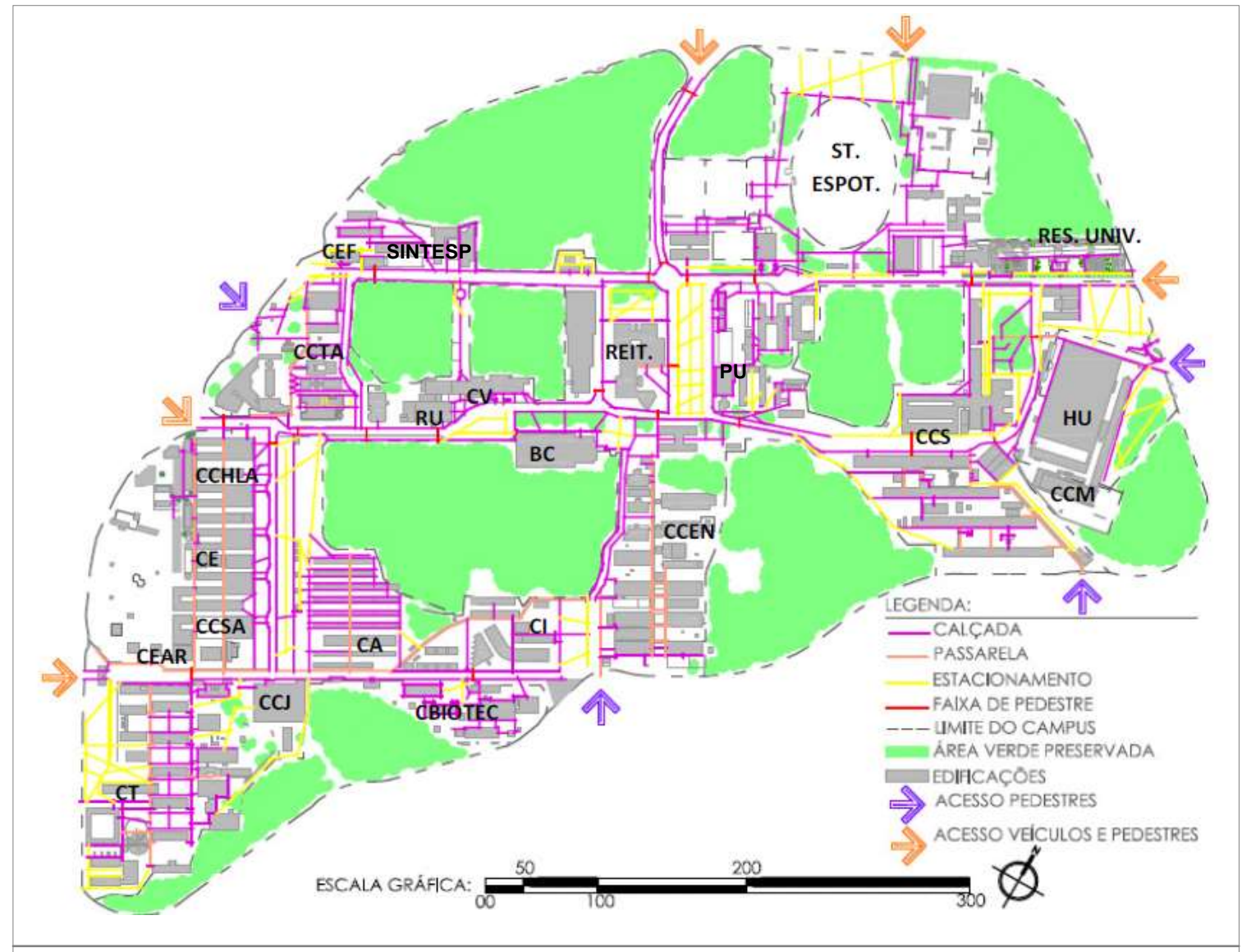

LEGENDA: Centro de Tecnologia (CT), o Centro de Ciências da Saúde (CCS), o Centro de Educação (CE), o Centro de Ciências Exatas e da Natureza (CCEN), o Centro de Ciências Humanas, Letras e Artes (CCHLA), o Centro de Ciências Sociais Aplicadas (CCSA), a Central de Aulas (CA), a Biblioteca Central (BC), o Restaurante Universitário (RU), o Centro de Ciências Jurídicas (CCJ), a Reitoria, o Centro de Vivências (CV), a Residência Universitária, o Setor de Segurança, a Caixa Econômica Federal (CEF), o Sindicato dos Trabalhadores do Ensino Superior (SINTESP), o Centro de Comunicação, Turismo e Artes (CCTA), o Hospital Universitário (HU), a Prefeitura Universitária (PU), o Centro de Ciências Médicas (CCM) e o Setor Esportivo.

Fonte: SARMENTO (2012).

\section{O OLHAR DO USUÁRIO}

A abordagem do usuário, em um primeiro momento, era feita com uma breve explicação do estudo, e em seguida o convite para participação da pesquisa. Em caso positivo, o questionário era entregue ao usuário e o pesquisador esclarecia qualquer dúvida que porventura viesse a surgir.

A amostra contou com $72 \%$ de usuários do sexo feminino e $28 \%$ do sexo masculino. A idade média dos respondentes (67\%) estava entre 18 e 25 anos, que é a faixa etária de grande parte dos discentes da Instituição.

Registrou-se apenas $4,5 \%$ da amostra composta por pessoas com deficiência, dividida em auditiva (6\%), física (29\%) e visual (65\%). Quando considerados os estratos, 3,5\% dos discentes apresentaram deficiência distribuída em 9\% auditiva, 18\% física e $73 \%$ visual; entre os docentes 5\% indicaram deficiência, sendo $50 \%$ física e $50 \%$ visual; e entre os técnicos 9,5\% indicaram deficiência, distribuída entre física (50\%) e visual (50\%). Não foram 


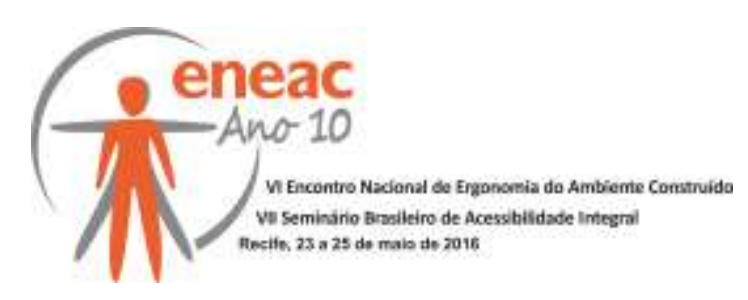

registradas pessoas com deficiência auditiva entre os docentes e os técnicos administrativos respondentes.

O tempo de vínculo (seja como discente, docente ou técnico) com o Campus entre os respondentes foi bem variado, estando entre menos de 1 ano $(24,5 \%)$, de 1 e 2 anos $(25,5 \%)$, de 3 a 4 anos (25,5\%), de 5 a 10 anos (14\%) e de mais de 10 anos (10,5\%). O percentual referente a menos de 5 anos é impulsionado pelos discentes, pois quando considerados os outros estratos o tempo de vínculo está entre 5 a 10 anos para $32 \%$ dos discentes e para $74 \%$ dos técnicos administrativos.

Apesar de grande parte dos respondentes ter menos de 5 anos de vínculo com a Instituição, quando considerada a frequência de visitas para o exercício da sua rotina de atividades, seja para trabalho ou estudo, 90,7\% da amostra indicou frequentar diariamente o campus, apenas $8,7 \%$ vem em dias alternados, $0,3 \%$ vem raramente e $0,3 \%$ não respondeu. Essa constância nas visitas da maioria dos usuários já indica que a amostra reunia condições para avaliar as estruturas de circulação da cidade universitária.

Os respondentes costumam circular por diversos locais da UFPB. Ressalta-se que muitos dos usuários indicaram visitar mais de um local, uma vez que há cursos com aulas distribuídas em mais de um centro de ensino. Os lugares mais frequentados pela amostra são o CT (32\%), o CCS (18\%), o CE (16\%), o CCEN (11\%), o CCHLA (9\%), o CCSA (7\%), a CA $(7 \%)$, a BC $(6 \%)$, o RU (3\%), o CCJ $(2 \%)$, a Reitoria (2\%), o CV (1\%), a Residência Universitária (1\%), o Setor de Segurança (1\%), a CEF $(0,8 \%)$, o SINTESP $(0,5 \%)$, o CCTA $(0,5 \%)$, o HU (0,3\%), a PU $(0,3 \%)$, o CCM $(0,3 \%)$ e o Setor Esportivo $(0,3 \%)$.

Quando perguntados sobre o principal meio de locomoção que utilizam para se deslocar pelo campus, $75 \%$ da amostra revelou utilizar-se da caminhada, 19\% utiliza o automóvel, $2 \%$ utiliza motocicleta, nenhum respondente indicou a bicicleta como meio de locomoção e $4 \%$ não respondeu a questão. Esse resultado mostrou-se fundamental, visto que a modalidade de deslocamento pedonal, foco do estudo, é utilizada por grande parte da amostra. Quando considerado apenas o grupo com deficiência (4,5\% da amostra) esse resultado também se reafirma, sendo um total de $64,7 \%$ dos usuários transitando a pé, 23,5\% utilizando automóvel e 11,8\% utilizando a motocicleta para se deslocar pelo campus.

Considerando o meio de locomoção entre os estratos, observa-se que o deslocamento a pé é realizado prioritariamente pelos discentes (Figura 3):

Figura 3 - Gráfico do principal meio de locomoção indicado pelos estratos.

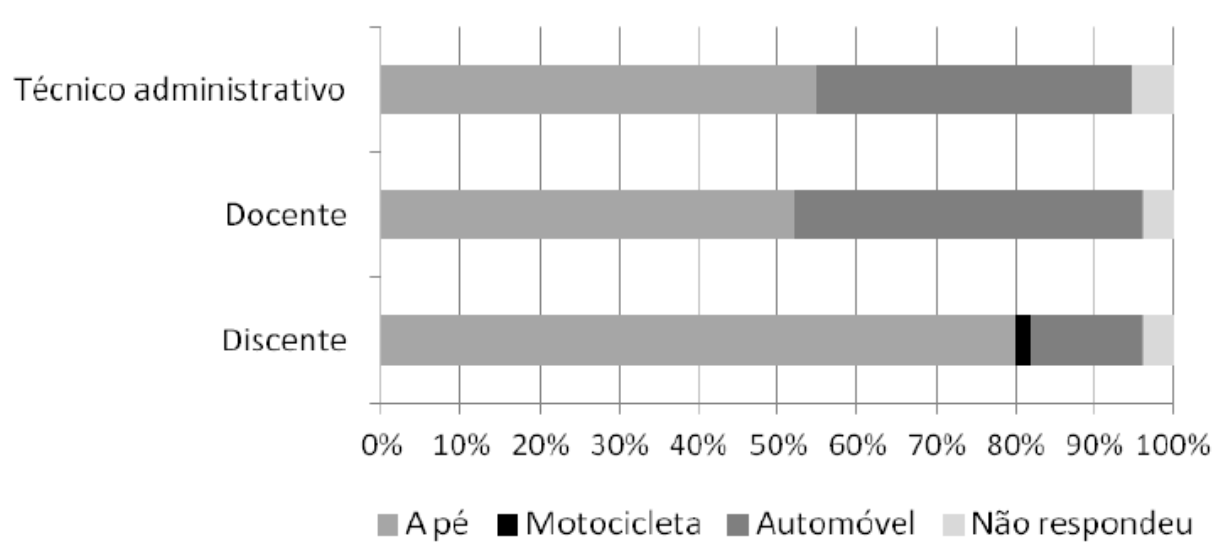

Fonte: Pesquisa de campo. 


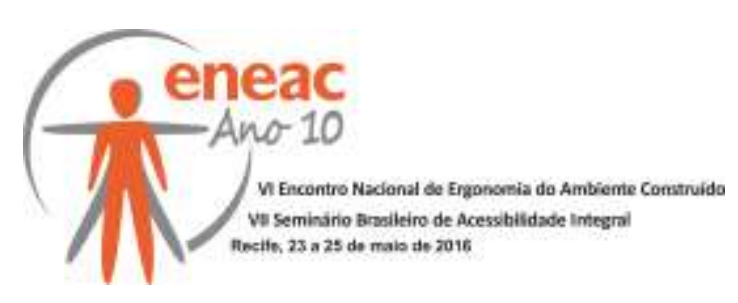

Os índices referentes à frequência e ao meio de locomoção apontam para uma considerável parcela de usuários com uma vivência diária realizada por meio de deslocamento pedonal, o que indica, mais uma vez, uma amostra apta para qualificar as estruturas de circulação de pedestres da Instituição.

Em relação à como a amostra classifica esses deslocamentos, $72 \%$ classificou como péssimo, 30\% como ruim, 10\% como regular, 0,8\% como bom e 0,2\% não respondeu. Porém, quando considerados apenas a qualidade do trajeto de seu desembarque, seja do ponto de transporte coletivo ou do estacionamento, até o seu destino habitual, os índices revelaram que $10 \%$ considera péssimo, $20 \%$ considera ruim, $45,5 \%$ classificou como regular, $22 \%$ como bom, $1,5 \%$ classificou como ótimo e $0,5 \%$ não respondeu. Dessa forma, pode-se dizer que os usuários sentem a necessidade de melhorias para o campus I como um todo, mas, apesar das dificuldades enfrentadas, estes já estão acostumados ao seu trajeto diário.

Após mencionarem a opinião sobre a condição do deslocamento, os respondentes deveriam indicar, dentre algumas opções, quais elementos dificultam seu deslocamento a pé pelo campus (Figura 4). Dentre as opções destaca-se a presença de obras, citada por $67 \%$ dos usuários, bem como a falta de passeios cobertos, citada por $53 \%$, e os desníveis, vistos por $44 \%$ da amostra. O percentual do item presença de obras pode ser atribuído as inúmeras construções em andamento no período, com tapumes ou entulho obstruindo a circulação do pedestre; já sobre a inexistência de cobertura no passeio pode-se dizer que esta foi considerada por grande parte dos respondentes em função do clima quente da cidade de João Pessoa ${ }^{2}$, que leva as pessoas a sentirem a necessidade de um percurso sombreado para caminhar.

Figura 4 - Gráfico dos elementos que dificultam o deslocamento da amostra pelo campus I.

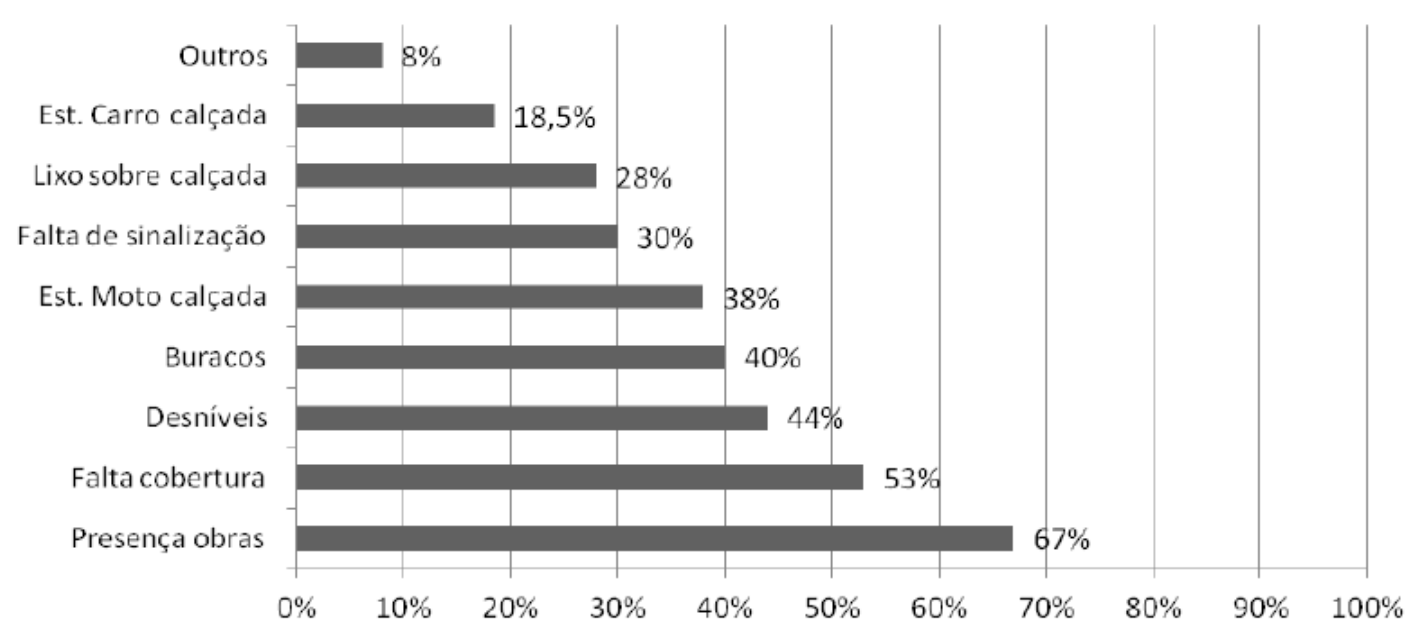

Fonte: Pesquisa de campo.

Ao extrair do gráfico (Figura 4) apenas a opinião do usuário com deficiência, têm-se que $82,4 \%$ apontou tanto os desníveis no piso como o estacionamento de motocicletas sobre a calçada como o principal elemento a dificultar o deslocamento pedonal pelo campus; $64,7 \%$ indicou a falta de sinalização; por $58,8 \%$ foram apontadas tanto a existência de buracos como a presença de obras; com $53 \%$ foi visto o estacionamento de carros sobre a calçada;

\footnotetext{
${ }^{2} \mathrm{O}$ clima da cidade de João Pessoa-PB é quente e úmido, do tipo intertropical, com temperaturas elevadas, variando entre $23^{\circ} \mathrm{C}$ e $29^{\circ} \mathrm{C}$, na maior parte do ano.
} 


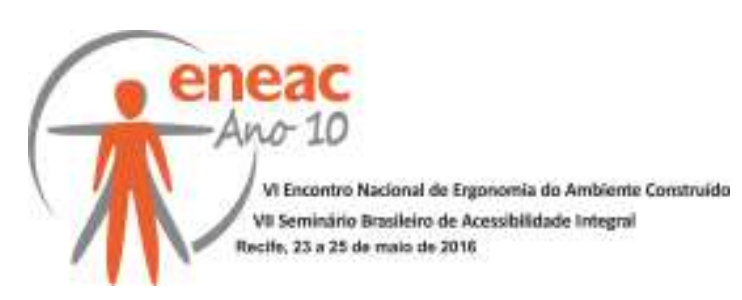

a falta de cobertura nas estruturas de circulação apresentou $35,3 \%$; e a presença de lixo em local inadequado indicada por $29,4 \%$ das pessoas com deficiência. Tais números apontam as principais barreiras enfrentadas no deslocamento dessa parcela de usuários pelo campus I da UFPB.

Além dos elementos listados na pergunta, parte da amostra indagada (8\%) (Figura 4) ainda mencionou outros fatores que porventura dificultam sua circulação no local, os mais citados foram:

- Ausência de calçadas em alguns locais;

- Ausência de rampas em lugares onde se fazem necessárias;

- Tráfego de motocicletas sobre calçadas;

- Pouca iluminação; e

- Presença de ambulantes em calçadas e passarelas reduzindo a área de circulação do pedestre.

Também foram constantemente citados fatores relativos ao pouco policiamento existente, o que demostra que, além de adequações na infraestrutura, a Instituição deve atentar para uma ampliação do número de seguranças circulando.

Quando indagados sobre a necessidade de um transporte público interno no campus, o qual inexiste, $67 \%$ da amostra afirmou que há necessidade da proposição, 32\% revelou que não sente falta e $1 \%$ não respondeu. Pode-se atribuir tais índices a extensa parcela de respondentes que circulam a pé $(75 \%)$. Esse resultado também se confirma entre as pessoas com deficiência.

No questionamento sobre a implantação do transporte público interno o usuário também poderia emitir o porquê de sua resposta, as principais respostas foram:

- "Para ajudar na locomoção das pessoas com deficiência." (Resposta de usuário sem deficiência).

- "Para proteger do sol." (Resposta de usuário sem deficiência).

- "Para evitar um aumento da circulação interna de veículos particulares" (Resposta de usuário sem deficiência).

- "Para reduzir o tempo de deslocamento quando temos que assistir aula em centros diferentes em um curto espaço de tempo." (Resposta de usuários com e sem deficiência).

- "Pela inexistência de calçadas." (Resposta de usuário sem deficiência).

- "Pelo policiamento insuficiente, principalmente no período noturno." (Resposta de usuário sem deficiência).

- "Para facilitar o acesso ao HU, a BC, a Residência Universitária, ao CV e ao Setor esportivo" (Resposta de usuários com e sem deficiência).

- "Para tornar o deslocamento mais rápido e confortável." (Resposta de usuário com e sem deficiência).

- "Para ajudar na locomoção e orientação." (Resposta de usuário com deficiência).

Vale destacar que parte da parcela que não indicou a necessidade de um transporte público interno para o campus, justificou da seguinte forma:

- "Tira o foco da acessibilidade para o pedestre." (Resposta de usuário com deficiência).

- "O tamanho do campus não justifica, necessitando apenas de melhorias da acessibilidade para o pedestre" (Resposta de usuário sem deficiência). 


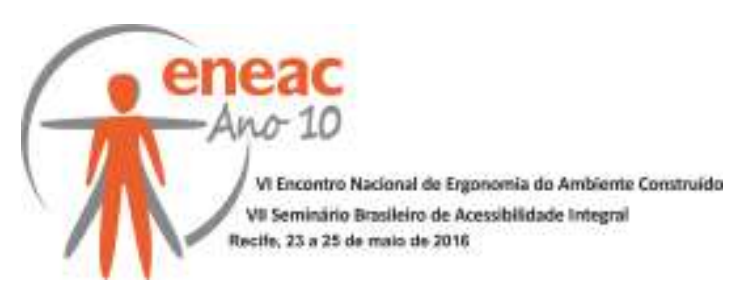

- "Gera o aumento do tráfego de veículos" (Resposta de usuário sem deficiência).

- "Há pontos de transporte coletivo próximo aos centros de ensino" (Resposta de usuário sem deficiência).

- "O nivelamento das passarelas e a construção de coberturas já seria suficiente" (Resposta de usuário sem deficiência).

- "Privilegia o sedentarismo" (Resposta de usuário com deficiência).

- "Não há estrutura no campus, pois as ruas são muito estreitas para a circulação de um transporte de grande porte" (Resposta de usuário sem deficiência).

- "Falta de sinalização" (Resposta de usuário sem deficiência).

Apesar da maioria da amostra (67\%) ter indicado a necessidade de implantação de um transporte coletivo para o campus, é possível perceber, a partir das respostas dos diversos usuários, que ações em prol da acessibilidade para a circulação do pedestre já seriam suficientes para a resolução de grande parte das dificuldades indicadas.

Os usuários também foram convidados a fazer um ranking em relação à preferência de caminho para andar a pé. Entre as opções estavam o caminho mais rápido, o mais seguro, o mais belo ou o melhor sombreado. Em primeiro lugar ficou o caminho mais rápido, indicado nessa colocação por $37 \%$ da amostra, e em último lugar a amostra indicou, com $74 \%$, a opção do caminho mais belo ou agradável visualmente. Esse índice reflete que a estética não é fator prioritário para o usuário no momento de escolher um caminho para circular. Destaca-se que, quando considerados os estratos da amostra em separado, $40 \%$ dos discentes mencionaram em primeiro lugar o caminho mais rápido, porém, $44 \%$ dos docentes e $60 \%$ dos técnicos administrativos apontaram como primeira opção o caminho mais seguro, o que significa que o usuário que se desloca principalmente a pé, ou seja, o discente (Figura 3), privilegia o caminho mais rápido e o usuário que se desloca principalmente por meio motorizado, ou seja, o docente e o técnico administrativo (Figura 3), busca maior segurança no percurso quando necessita se locomover a pé.

Sobre o mobiliário urbano a amostra pôde qualificar o estado físico em que se encontra (Figura 5). O resultado demonstra quem os usuários percebem a ineficiência das poucas placas de sinalização, bebedouros e orelhões existentes, além da má conservação das lixeiras, postes, bancos e mesas disponíveis.

Figura 5 - Gráfico da opinião do usuário sobre o estado físico do mobiliário urbano.

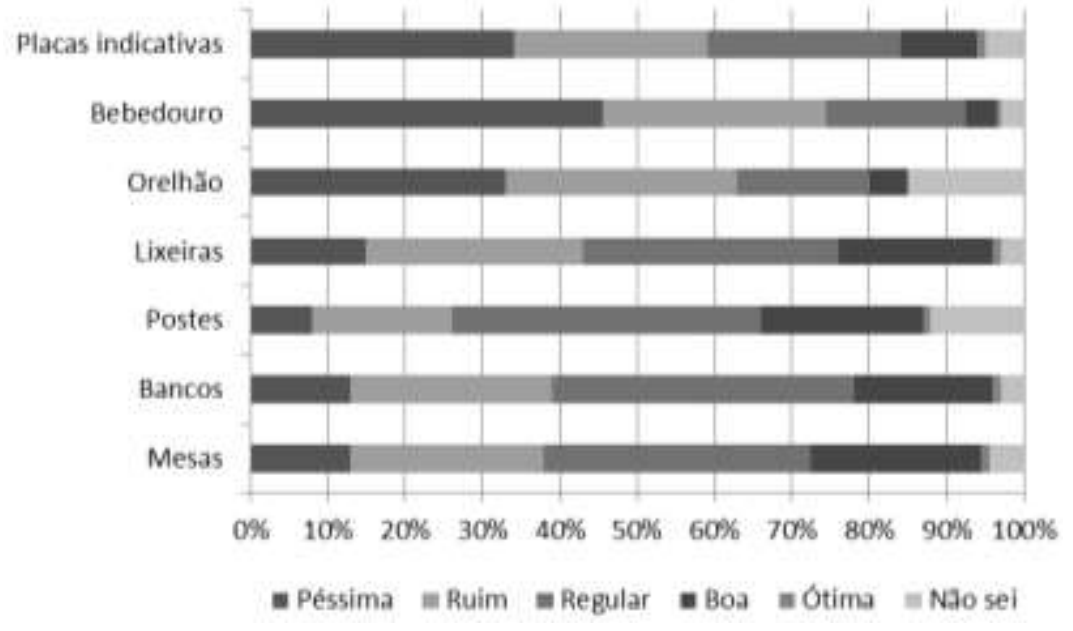

Fonte: Pesquisa de campo. 


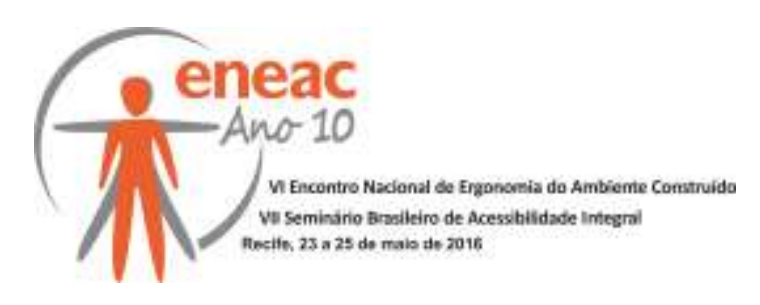

Os usuários foram consultados sobre 3 itens que não poderiam deixar de ser implantados no campus, seja pelo fato de inexistirem ou por existirem em quantidade insuficiente, os mais citados já estão presentes no campus e referem-se ao mobiliário urbano, a saber: poste de iluminação com 49\%, bebedouro com 44\% e lixeira com 38\% (Figura 6). Destacase que no ano de 2011 foi ampliado o número de lixeiras a partir da atuação do Projeto de Educação Ambiental - Coleta Seletiva Solidária na UFPB. Porém, esse mobiliário ainda é visto como insuficiente pela amostra. Os itens referentes à sinalização também apontaram representativo percentual, sendo a sinalização tátil citada por $34 \%$ dos respondentes, as placas indicativas nas edificações por $33 \%$ e a faixa de pedestre por $28 \%$ da amostra (Figura 6).

Ao considerar apenas o percentual de usuários com deficiência (4,5\% da amostra) os 3 itens mais citados para implantação foram a sinalização tátil com $76,5 \%$, o poste com sinal sonoro junto as faixas de pedestres e o poste de iluminação, ambos com 47,5\% e as placas identificando as edificações com $35,3 \%$.

Figura 6 - Gráfico dos itens que não poderiam deixar de ser implantados no campus I.

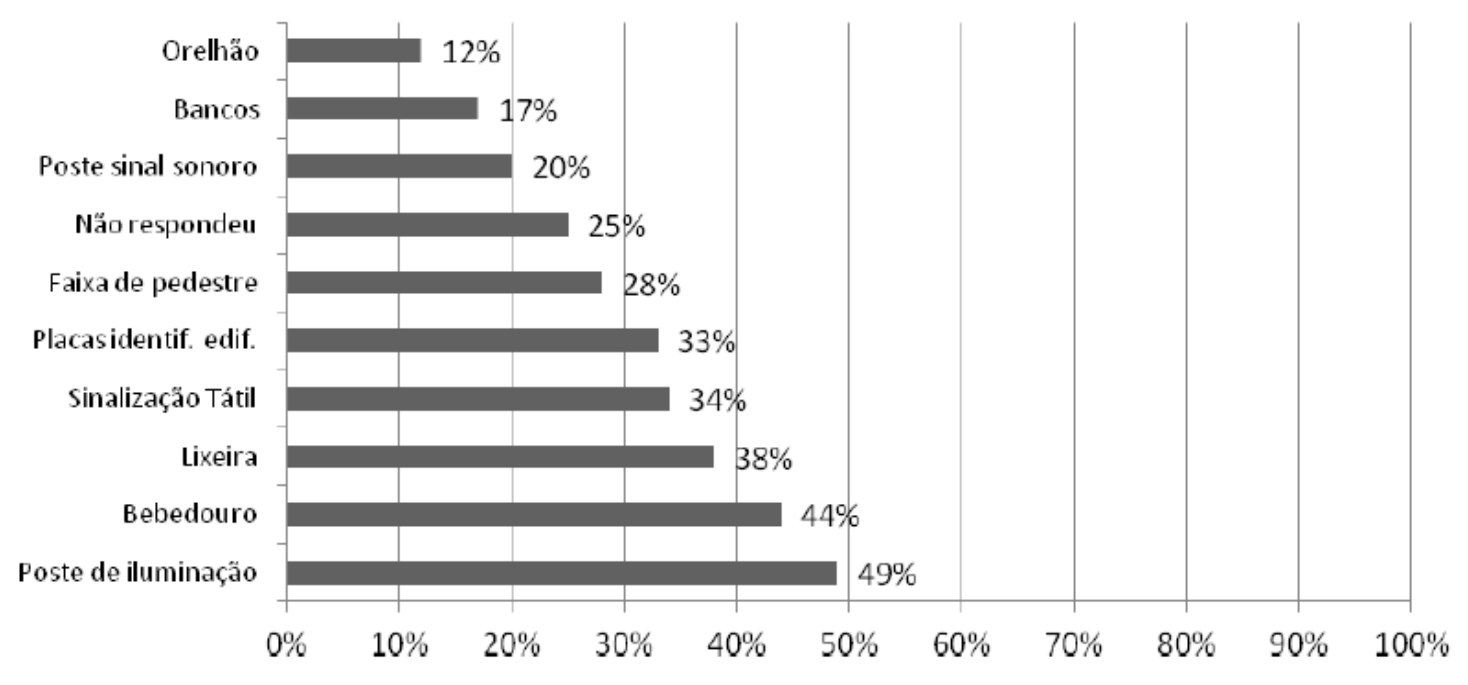

Fonte: Pesquisa de campo.

Nas questões sobre os estacionamentos os usuários tiveram a oportunidade de avaliar sua condição geral, a suficiência das vagas e a identificação das vagas destinadas às pessoas com deficiência. Entre os respondentes, 30\% considerou regular a situação dos estacionamentos, $28 \%$ considerou ruim, 25,5\% avaliou como péssima, 10,5\% avaliou como boa, apenas $1 \%$ avaliou como ótima e $5 \%$ não respondeu. Sobre a quantidade de vagas, a grande maioria (83\%) julgou que as vagas existentes são insuficientes. Apenas $15 \%$ considerou suficiente as vagas existentes e $2 \%$ não respondeu a pergunta. Tais índices se aproximam dos indicados na identificação das vagas para pessoas com deficiência, tendo $88 \%$ citado não identificar facilmente as vagas para pessoas com deficiência presentes em alguns dos estacionamentos do campus; apenas $9 \%$ apontou identificá-las e $3 \%$ preferiu não responder a pergunta. Pode-se relacionar a não identificação das poucas vagas existentes ao fato dessas estarem sinalizadas em desacordo com o recomendado pela NBR 9050 (ABNT, 2015).

Os usuários também puderam expressar sua opinião a respeito da comunicação e sinalização existentes. Quando indagados sobre a orientação do deslocamento a pé pelo campus, $33 \%$ considerou regular, $32 \%$ avaliou como ruim, $25,5 \%$ a viu como péssima, 


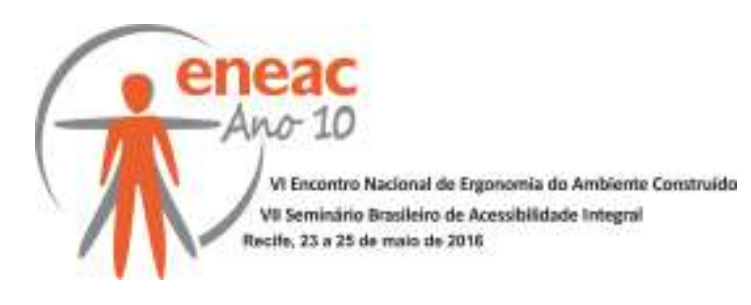

somente $8,5 \%$ classificou como boa e $1 \%$ da amostra não respondeu. Os usuários também opinaram sobre a suficiência da sinalização presente no campus, onde $91 \%$ classificou como insuficiente e apenas $9 \%$ indicou como suficiente. Ratificando tais índices, a maioria dos usuários (93\%) indicou que no momento em que precisa ir pela primeira vez a algum lugar do campus necessita perguntar a outras pessoas, uma vez que, a orientabilidade por meio das placas existentes não satisfaz.

Sobre a quantidade de faixas de pedestres, $68 \%$ dos usuários considerou que estas deveriam existir em maior número, $30 \%$ acredita que as já existentes são suficientes e $2 \%$ da amostra preferiu não responder a questão.

\section{CONSIDERAÇÕES FINAIS}

Segundo Ubierna (1994), o objetivo da acessibilidade é proporcionar mobilidade; e a avaliação da acessibilidade, sob o olhar do pedestre, realizada no sistema de circulação de pedestres do campus I da UFPB demonstrou deficiências, que comprometem a mobilidade do usuário. Indicando que a condição do deslocamento é dificultada principalmente pela construção civil, que obstrui a faixa de circulação de pedestres com tapumes ou entulhos de obras; seguida pela falta de cobertura em passarelas, deixando grande parte do trajeto no sol; desníveis acentuados em alguns pontos e quebras no piso, que indicam a falta de manutenção constante; estacionamento irregular de motocicletas sobre as calçadas e passarelas, gerando inúmeras barreiras atitudinais; e a falta de sinalização. Os usuários também citaram a má qualidade dos poucos bebedouros, placas indicativas e telefones públicos existentes; como também, solicitaram instalação de postes de iluminação, lixeiras, placas indicativas e faixas de pedestre. Nos estacionamentos identificaram a insuficiência de vagas, e, em especial, de vagas exclusivas para pessoas com deficiência. Sobre a comunicação e sinalização, esta se mostrou insuficiente, levando o usuário a buscar informações de orientação com outros frequentadores do campus.

Muitos dos aspectos apontados pelos usuários continuam sem solução, o que aponta para a necessidade da elaboração de um programa de manutenção permanente dessas estruturas, com uma equipe atuante em campo, além da implantação de rotas acessíveis, de modo que as deficiências identificadas no sistema sejam resolvidas adequadamente sem que causem limitações no deslocamento de qualquer usuário.

\section{REFERÊNCIAS BIBLIOGRÁFICAS}

ASSOCIAÇÃO BRASILEIRA DE NORMAS TÉCNICAS. NBR 9050: Acessibilidade a edificações, mobiliário, espaços e equipamentos urbanos. Rio de Janeiro: ABNT, 2015.

BAPTISTA, A.H.N. Proposição da Teoria da Acessibilidade Efetiva com plano de verificação para estruturas de circulação de pedestre. 2010. Tese (Pós-Graduação em Desenvolvimento Urbano) UFPE, Recife: abril, 2010. 325 p.

BINS ELY, V. H. M.; GHIZI, D. M. Acessibilidade e Orientabilidade no Campus da Universidade Federal de Santa Catarina. In: 6 Ergodesign. Anais... São Paulo: Bauru, 2006.

CostA, A. D. L.; CeVAdA, C. M.; VIANA, E.; RODRIGUES, J.; LIRA, R. Gestão do Solo Universitário: o Campus da UFPB no Brasil. In: $4^{\circ}$ Congresso Luso-Brasileiro para o Planejamento Urbano, Regional, Integrado, Sustentável, (Pluris 2010). Anais... Faro, Portugal: 2010. 


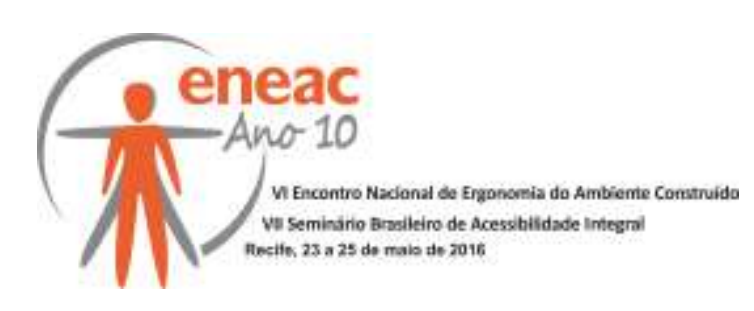

DUARTE, C. R. de S.; COHEN, R. Acessibilidade aos Espaços do Ensino e Pesquisa: Desenho Universal na UFRJ - Possível ou Utópico? In: NUTAU 2004: DEMANDAS SOCIAIS, INOVAÇÕES TECNOLÓGICAS E A CIDADE, 2004, São Paulo. Anais... São Paulo: USP, 2004.

GUNTHER, H. Como elaborar um questionário. In: PINHEIRO, J. Q.; GUNTHER, H. (Org.). Métodos de pesquisa nos estudos pessoa-ambiente. São Paulo: Casa do Psicólogo, 2008. p. 105-148.

GÜNTHER, H; ELALI, G. A.; PINHEIRO, J. Q. A abordagem multimétodos em Estudos PessoaAmbiente: características, definições e implicações. In: PINHEIRO, J. Q.; GÜNTHER, H. (Org.). Métodos de pesquisa nos estudos pessoa-ambiente. São Paulo: Casa do Psicólogo, 2008, p. 369396.

ORNSTEIN, S.W. Desenho Universal: acessibilidade para todos. Entrevista concedida por Sheila Walbe Ornstein ao SESI - Serviço Social da Indústria, em 19 de abril de 2011. Disponível em <http://mercadoetico.terra.com.br/arquivo/desenho-universalacessibilidade-para-todos/>. Acesso em: 15 de mai. 2011.

ORNSTEIN, S. W.; ROMÉRO, M.(col). Avaliação Pós Ocupação do Ambiente Construído. SP: Studio Nobel, 1992.

RHEINGANTZ, P.A.; AZEVEDO, G.A.; BRASILEIRO, A.; ALCANTARA, D. de; QUEIROZ, M. Observando a qualidade do lugar: Procedimentos para a avaliação pós-ocupação. Coleção PROARQ. FAU/UFRJ. Rio de Janeiro/RJ, 2009.

SARMENTO, B.R. Acessibilidade em sistema de circulação de pedestre: Avaliação do campus I da UFPB. Dissertação (Arquitetura e Urbanismo). Universidade Federal da Paraíba. João Pessoa-PB: 2012.

SOMMER, B.; SOMMER, R. A Practical Guide to Behavioral Research: tools and techniques. New York: Oxford University Press, 2002.

STEVENSON, William. Alfredo Alves de Faria (tradução). Estatística Aplicada à Administração. São Paulo: Harper \& Row do Brasil, 1981.

UBIERNA, J.A.J. Recomendações para Acessibilidade no Transporte. In: In: Curso Básico sobre Acessibilidade ao Meio Físico e VI Seminário sobre Acessibilidade ao Meio Físico. Anais... Brasília: Corde, 1994.

VASCONCELLOS, E.A. Transporte urbano, espaço e equidade: análise das políticas públicas. São Paulo: Annablume, 2001. 218p.

UNIVERSIDADE FEDERAL DA PARAÍBA (UFPB). Projeto UFPB - REUNI. João Pessoa: UFPB. 2007.

UNIVERSIDADE FEDERAL DA PARAÍBA (UFPB). Guia do Calouro 2011 UFPB. 2011. 